\title{
Evaluation of dispersability of gamma alumina prepared by homogeneous precipitation
}

\author{
Adrián ZAMORATEGUI, ${ }^{\dagger}$ Satoshi SUGITA, Ramón ZÁRRAGA, Satoshi TANAKA* and Keizo UEMATSU* \\ Department of Chemistry, University of Guanajuato, Guanajuato, Gto., Mexico. Col. Noria Alta s/n; CP 36050 \\ *Department of Materials Science and Technology, Nagaoka University of Technology, \\ 1603-1 Kamitomioka, Nagaoka 940-2188, Japan
}

\begin{abstract}
Aqueous dispersions of $\gamma$-alumina powder synthesized by homogeneous precipitation (HP) were investigated and compared with a commercial gamma alumina (TM300). As the isoelectric point (IEP) of the two powders was found to be at the same pH (8.5), the rheological properties of the suspensions were determined under controlled rate conditions, varying the pH and solid loading. It was found that the $\mathrm{pH}$ used in a suspension affects its rheological properties and consequently the final density of the slip cast body, obtaining the highest density for the heated bodies at $\mathrm{pH}$ values below the IEP. The $\mathrm{pH}$ limit to maintain Newtonian flow is dependent on the solid content and the type of alumina used. Thus, a TM300 35\% solid-loaded suspension requires a pH of 4, whereas HP alumina requires only a $\mathrm{pH}$ of 3.75 to behave as a Newtonian fluid. Both suspensions were slip cast and the green bodies were heated at four distinct temperatures. Lastly, the relative densities of the heated bodies were measured by the Archimedes method, and in all cases, lower relative densities were obtained for HP alumina.
\end{abstract}

(C)2012 The Ceramic Society of Japan. All rights reserved.

Key-words : $\gamma$-alumina, Homogeneous precipitation, Slip cast, Porous compact

[Received January 5, 2012; Accepted May 7, 2012]

\section{Introduction}

Colloidal processing is an ancient and still a very widespread technique for the manufacture of all kind of ceramic materials. In recent years, nano-sized oxides have been used as precursors in an attempt to obtain a finer microstructure in the final sintered product. However, the nanopowders show a strong tendency to agglomerate due to their high surface area and high free energy, ${ }^{1)}$ decreasing the homogeneity of the slurry. This tendency can be used advantageously to make porous ceramics, where it becomes necessary to carefully tune rheological parameters to prepare stable suspensions ${ }^{2), 3)}$ so porous materials with valuables properties such as low density, high surface area, high porosity and low thermal conductivity can be obtained. Sedimentation and apparent viscosity measurements at fixed shear rates are some techniques widely used in assessing this stability, making it possible to produce high homogeneous and stable suspensions by means of manipulating interparticle forces. ${ }^{4)-6)}$ Based on DLVO theory (named after Derjaguin-Landau-Verwey-Overbeek), a stable colloidal suspension is obtained when the attractive van der Waals forces remain weaker than the interparticle electrostatic repulsion The latter is produced either after dissociation of surface species or by adsorption of ions from the suspending liquid. Furthermore, steric repulsive forces can be generated by means of anchoring polymers on the surface of the particles. ${ }^{7)-9)}$ An indirect way to evaluate the resulting effect between the competitive van der Waals forces and electrostatic forces is to perform a rheological analysis of the suspensions. ${ }^{10)}$

From the economic and safety points of view, water is generally the most common vehicle used in the preparation of alumina slip for casting. Furthermore, water is an excellent solvent for many processing additives, which also play an important role in

Corresponding author: A. Zamorategui; E-mail: zamorategui@ ugto.mx the viscosity of the suspension by modifying the interface energy between alumina and water. ${ }^{11), 12}$ ) The fluidity and stability of a colloidal suspension can be controlled by adjusting its $\zeta$-potential. Due to its amphoteric properties, alumina tends to be positively charged at low $\mathrm{pH}$ values and negatively charged at high $\mathrm{pH}$ values. Thus, the $\zeta$-potential is affected by changes in $\mathrm{pH}$, nature of the electrolyte used, and its ionic strength. ${ }^{13), 14)}$ In this paper the effect of $\mathrm{pH}$ is evaluated according to the rheological behavior of dispersions of anisotropic $\gamma-\mathrm{Al}_{2} \mathrm{O}_{3}$ particles synthesized by homogeneous precipitation, compared with morphologically more uniform (spherical) $\gamma-\mathrm{Al}_{2} \mathrm{O}_{3}$ particles $\left(\mathrm{TM}-300^{\mathrm{TM}}\right.$ ).

Homogeneous precipitation as described by Sugita et al. ${ }^{15}$ ) is a methodology that makes it possible to obtain $\gamma$-alumina powder consisting of agglomerates with a narrow particle size distribution ${ }^{16)-18)}$ composed of fibrillar particles. In the $\gamma$-phase, alumina possesses a large surface area, high pore volume, and great catalytic properties which strongly depend on its crystalline structure. $^{19)-21)}$

From all the different powder processing techniques used currently in industry it is well known that the properties achieved in the final products depend strongly on the morphology of the powders employed, which is in turn dependent on the chemical composition and the experimental conditions used during its own synthesis. A small variation in a powder processing condition can greatly affect the microstructure of the final ceramics. ${ }^{22)}$ So, in order to improve ceramic quality, i.e. avoiding defects in the microstructure, it is crucial to evaluate the characteristics of the starting materials and their behavior during processing. They should comprise a calibrated powder or paste with convenient rheological properties which depend on particle size, morphology and solid content. ${ }^{23), 24)}$ Colloidal suspensions are commonly analyzed by rheological techniques which are also used as quality control standards that attempt to minimize variation in suspensions prior to performing the consolidation procedure, i.e. slip cast ${ }^{25), 26)}$ so as to control and optimize the microstructure of 

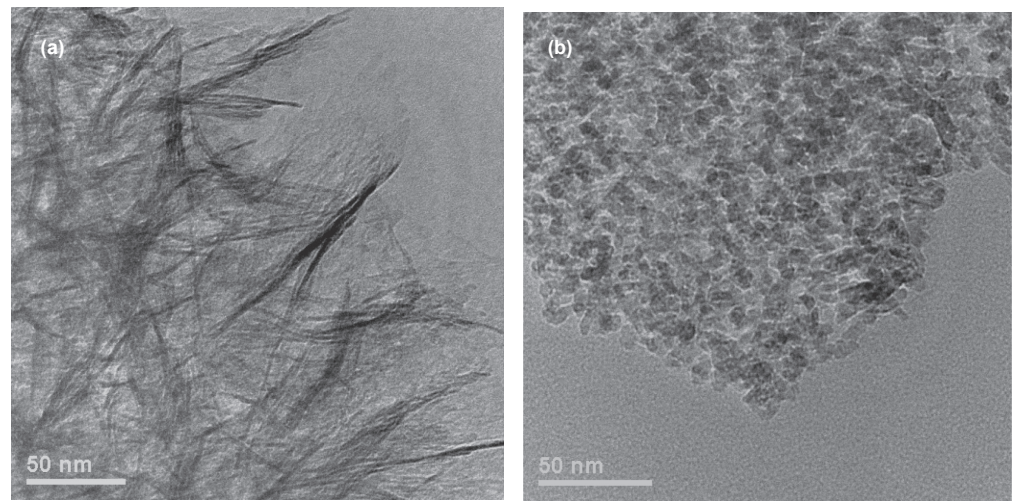

Fig. 1. TEM micrographs of (a) HP and (b) TM300 $\gamma$-alumina.

the final ceramic. Thus, the consolidated suspension requires a source containing the highest particle content and lowest viscosity possible which can be related to a high particle mobility. ${ }^{27)}$ The purpose of this study is to observe the effect of particle morphology on the relative density of slip cast ceramic bodies measuring and controlling viscosity of nano-powder slurries.

\section{Experimental procedure}

Two different powders of gamma alumina were compared. The first was a commercial Taimicron powder TM-300 ${ }^{\mathrm{TM}}(99.99 \%$ pure, mean particle size of $7 \mathrm{~nm}$ and specific surface area $=220$ $\mathrm{m}^{2} \mathrm{~g}^{-1}$, Taimei Chemicals Co., Japan). The second was prepared in the laboratory following the methodology of homogeneous precipitation (HP) as described by Sugita et al: ${ }^{15)}$ spherical submicron particles of basic aluminum sulfate (BAS) are synthesized from a mixture of aluminum sulfate and ammonium bisulfite solutions. This BAS is then neutralized in a solid/liquid reaction with ammonia solution in order to transform it to aluminum hydroxides. Then, the hydroxides are oven dried at $110^{\circ} \mathrm{C}$ to obtain pseudoboehmite $(\mathrm{AlOOH})$ which is in turn used as $\gamma$ alumina precursor since it transforms to this phase at $450^{\circ} \mathrm{C}^{28)-30 \text { ) }}$

Once obtained, a higher specific surface area $\left(334 \mathrm{~m}^{2} \mathrm{~g}^{-1}\right)$ was measured for the HP alumina (determined by single-point BET measurements (ASAP 2010 Micromeritrics Instrument Corp., USA). The morphology and size of the powders were examined by transmission electron microscopy (TEM; Phillips Tecnai F-20 field emission microscope). X-ray diffraction was used to determine the purity of the phase using $\mathrm{Cu} \mathrm{K} \alpha$ radiation (XRD, MO3XHF22; Mac Science Ltd., Japan). The average diameter of the agglomerates was measured using a $10 \mathrm{mM}$ solution of $\mathrm{KCl}$ by the electroacoustic technique with a particle size analyzer (AcoustoSizer II, ESA; Colloidal Dynamics, USA). The variation on $\zeta$-potential was determined by electrophoretic mobility.

Eight dispersions for each type of $\gamma$-alumina were prepared using $10,15,20,25,30,35,40$ and $45 \mathrm{wt} \%$ of solid content with a milling medium of $90 \mathrm{~g}$ of 2-mm zirconia beads introduced into an attrition mill. Hydrochloric acid and ammonium hydroxide were added to adjust the $\mathrm{pH}$ (from 4 to 10 ), milling for $6 \mathrm{~h}$. The rheological behavior of the suspensions was observed using a standard concentric cylinder rheometer (Physica MCR 300 Anton Paar) at $25^{\circ} \mathrm{C}$. After that, the samples were slip casted into $25 \mathrm{~mm}$ diameter cylindrical rubber molds, allowing the green bodies obtained to dry under atmospheric conditions. Finally, the bodies were heated at temperatures of $400,600,900$ and $1250^{\circ} \mathrm{C}$, respectively. The green body densities were determined by the mass-volume measurement technique whereas the densities of calcined bodies were measured by the Archimedes method. The

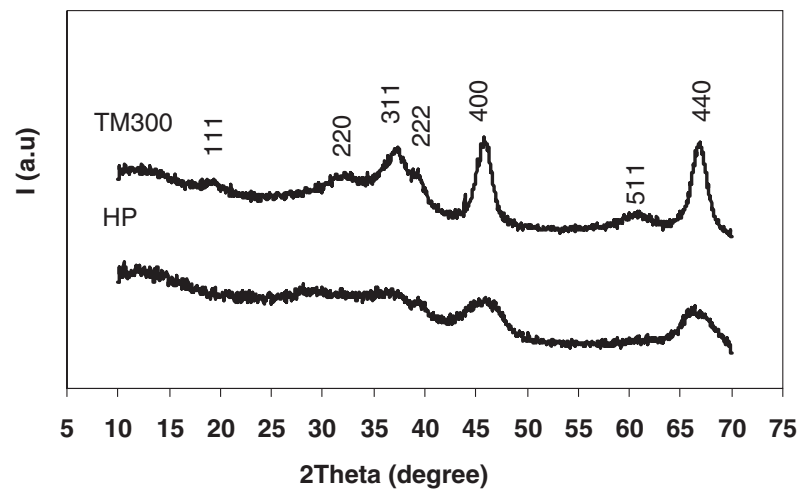

Fig. 2. X-ray diffraction pattern for HP and TM300 $\gamma$-aluminas.

relative densities were calculated considering the following real densities: $3,3.37$ and $3.98 \mathrm{~g} \mathrm{~cm}^{-3}$ for the gamma, theta, and alpha alumina phases, respectively. A scanning electron microscope (SEM) (JEOL JSM-6400) was used to observe the microstructure on the surface of the bodies.

\section{Results and discussion}

\subsection{Powder characterization}

The different arrangements in the agglomerates of each type of alumina are shown in Fig. 1. According to the specific surface area $\left(334 \mathrm{~m}^{2} \mathrm{~g}^{-1}\right)$ an average length of $75 \mathrm{~nm}$ and a diameter of $3 \mathrm{~nm}$ (approx.) was calculated per fiber, corresponding to an aspect ratio of 25 , which is in agreement with the dimensions observed in Fig. 1(a); in contrast, the TM300 alumina consisting of spherical particles less than $10 \mathrm{~nm}$ in diameter [Fig. 1(b)] correspond to an aspect ratio of 1 . The higher specific surface area observed for HP is a consequence of its fibrous arrangement.

The XRD patterns for HP and TM300 $\gamma$-aluminas are shown in Fig. 2. The peaks observed match well with those reported in JCPDS No. 10-0425 for $\gamma-\mathrm{A}_{2} \mathrm{O}_{3}$. However, important differences can be noticed as the TM300 powder presents significantly sharper and more intense peaks, indicating a higher crystalline structure than that observed for the HP powder.

\subsection{Suspension characterization}

The stability of a suspension can be measured in terms of the value of its $\zeta$-potential. So, the value of the $\zeta$-potential corresponding to changes in surface charge for HP and TM300 as $\mathrm{pH}$ varies are depicted in Fig. 3, showing the characteristic shape and isoelectric point typical for $\gamma$-alumina. In both samples, the IEP was found to be at $\mathrm{pH} 8.5$, which is consistent with previously reported data. ${ }^{8), 20)}$ 


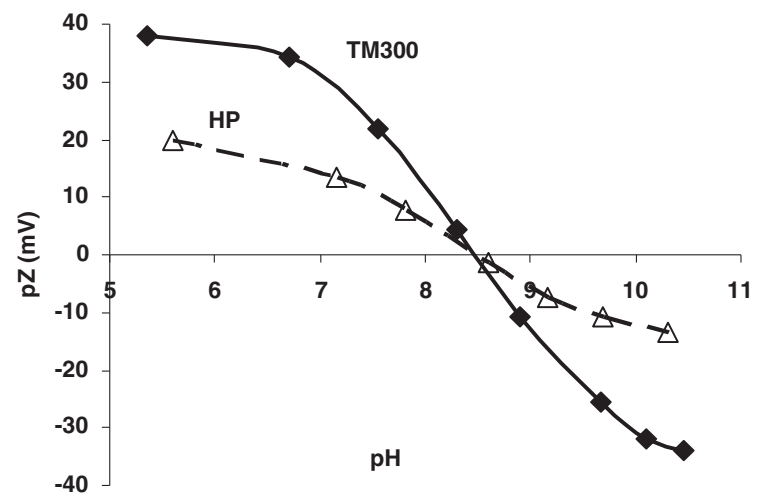

Fig. 3. $\zeta$-potential curves for HP and TM300 $\gamma$-aluminas as a function of $\mathrm{pH}$.

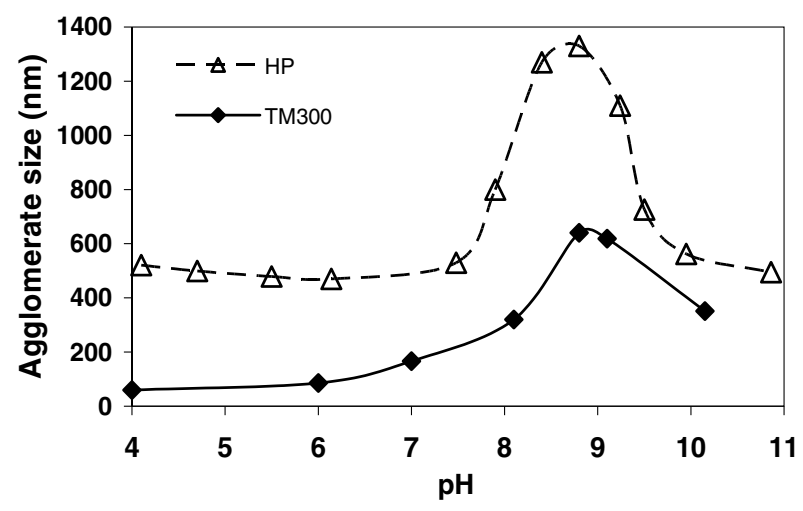

Fig. 4. Effect of $\mathrm{pH}$ on the mean size for HP and TM300 agglomerates.

As can be seen, the $\zeta$-potential in TM300 is always higher than those values observed for HP suspension either below or above the IEP, i.e., for the particles negatively and positively charged. For $\mathrm{pH}$ below 6.5 the TM300 $\zeta$-potential is higher than $35 \mathrm{mV}$, indicating that well dispersed suspensions of this powder can be obtained, unlike to HP powder suspensions that would tend to agglomerate at the same $\mathrm{pH}$ due to their lower $\zeta$-potential $(18 \mathrm{mV})$.

$5 \mathrm{wt} \%$ aqueous suspensions of TM300 and HP powders were prepared in order to evaluate the effect of $\mathrm{pH}$ on the agglomerate size by the electroacoustic method. Figure 4 shows the agglomerate size obtained in both cases as a function of $\mathrm{pH}$. Below $\mathrm{pH} 6$, the size for TM300 and HP agglomerates remains below 100 and $550 \mathrm{~nm}$, respectively. A dramatic increase in size can be observed at $\mathrm{pH}$ between 7 and 8.7 , indicating that relevant flocculation takes place in both cases at around the IEP. It is noticeable that agglomerates of TM300 remain always smaller than those of HP. As the last are made of nanofibers, there is a tendency to agglomerate more than the spherical nanoparticles of TM300 due to their higher surface energy. The degree of agglomeration in this case seems to be a result of geometric effects and consequently due to the surface area of each kind of particles. For the same reasons, the value of the $\zeta$-potential for HP always remains below TM300, as was shown in Fig. 3.

Since agglomerate size is influenced by $\mathrm{pH}$, the viscosity of HP and TM300 suspensions was evaluated at a low concentration $(15 \mathrm{wt} \%)$ varying the $\mathrm{pH}$. The effect of $\mathrm{pH}$ on the viscosity of the suspensions at a given shear rate $\left(100 \mathrm{~s}^{-1}\right)$, is shown in Fig. 5. Relatively low viscosities below $\mathrm{pH} 6.0$ are observed in both

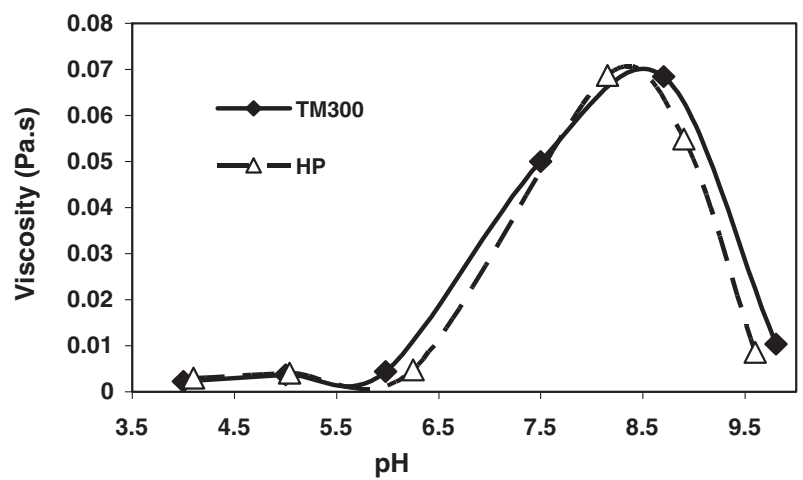

Fig. 5. Viscosities of the $15 \mathrm{wt} \%$ of HP and TM300 suspensions as a function of $\mathrm{pH}$ at a shear rate of $100 \mathrm{~s}^{-1}$.

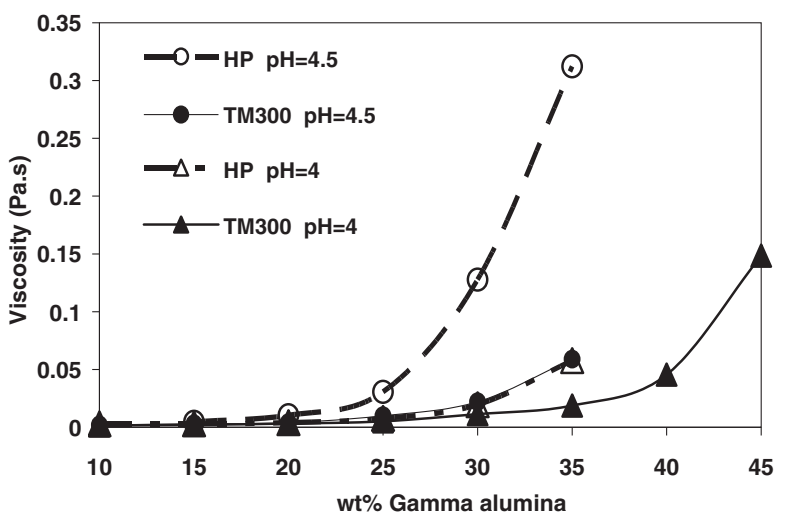

Fig. 6. Viscosity at $100 \mathrm{~s}^{-1}$ as a function of solid loading at $\mathrm{pH} 4$ and 4.5.

cases, which is in agreement with the high $\zeta$-potential values measured at those $\mathrm{pHs}$. The viscosity drastically increases from $\mathrm{pH}$ 6, reaching its maximum at about $\mathrm{pH} 8.5$ (IEP). Once there, high flocculation occurs due to electrostatic repulsion decreasing as it becomes comparable to the interparticle van der Waals attractive forces. Once again, the viscosity decreases at around pH 9.5 as the particles become increasingly negatively charged. So, the amount of charge on the surface of the particles (measured as $\zeta$-potential) generates deflocculation above and below the IEP, yielding colloidally stable suspensions. In contrast, close to the IEP the flocculation of the particles generates suspensions that are colloidally unstable.

The effect of the solid content on the viscosity was evaluated varying the $\mathrm{pH}$. Figure 6 shows the viscosity at $100 \mathrm{~s}^{-1}$ as a function of the solid loading at two $\mathrm{pH}$ values (4 and 4.5). The HP suspension resulted always more viscous than TM300. This behavior can be adscribed as a result of the difference of the aspect ratio between the two different particles which leads to a higher specific surface area for the HP powder (332 vs 220 $\mathrm{m}^{2} \mathrm{~g}^{-1}$ for TM300). Powders with higher aspect ratio tend to agglomerate more, increasing the viscosity of the suspension. Thus, a viscosity of $0.3123 \mathrm{~Pa} \cdot \mathrm{s}$ for $\mathrm{HP}$ vs $0.059 \mathrm{~Pa} \cdot \mathrm{s}$ for TM300 suspensions with $35 \mathrm{wt} \%$ at $\mathrm{pH} 4.5$ was observed.

Thus, in order to prepare a stable suspension with high solid content it is necessary to adjust the $\mathrm{pH}$ at an adequate acid value to lower viscosity by reducing interparticle interactions. Furthermore, the rheological behavior of the $\gamma$-alumina suspensions is not only affected by the solid morphology and $\mathrm{pH}$, but also the solid loading plays a determinant role on in viscosity. 


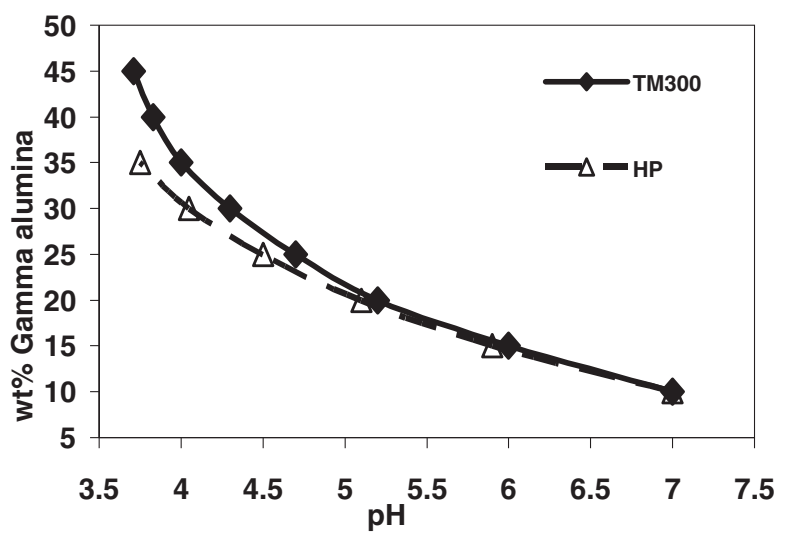

Fig. 7. Effect of solid loading and $\mathrm{pH}$ on the Newtonian flow for TM300 and HP.

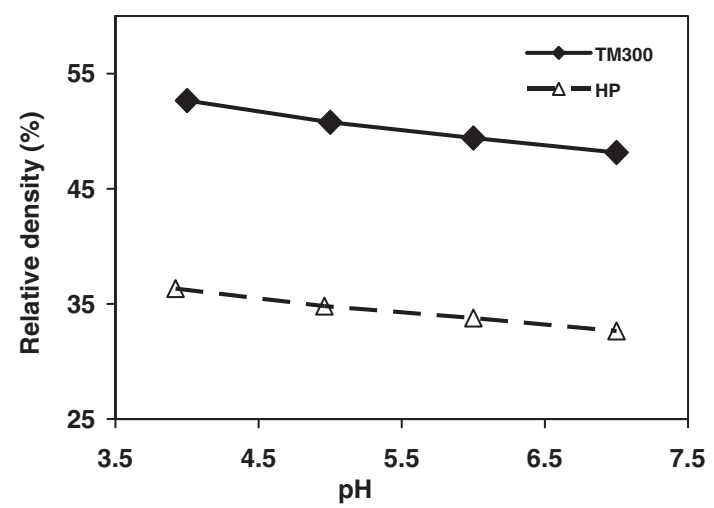

Fig. 8. Effect of $\mathrm{pH}$ on the relative density of $\mathrm{HP}$ and TM300 sintered bodies $\left(1250^{\circ} \mathrm{C}\right)$ produced by slip casting using $25 \mathrm{wt} \%$ suspensions.

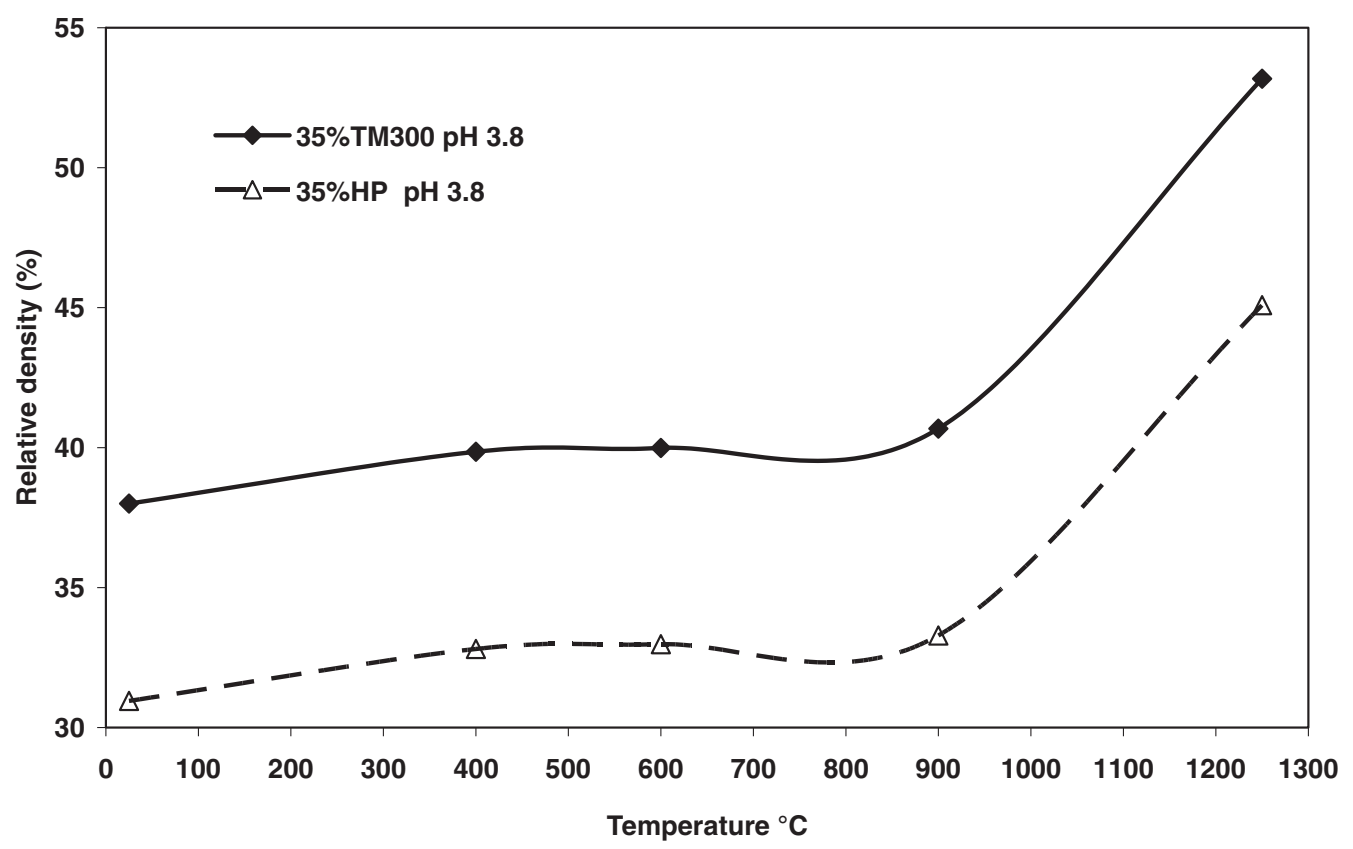

Fig. 9. Relative density of the bodies as a function of heated temperature.

Figure 7 shows the effect of solid loading and $\mathrm{pH}$ on the limit of Newtonian flow for TM300 and HP. The maximum allowed solid concentration for TM300 was 45 and $35 \mathrm{wt} \%$ for the HP (at around $\mathrm{pH} 3.7$ ).

\subsection{Porous compacts}

As it is well known, viscosity and $\zeta$-potential are intrinsically related in a suspension; in general a high $\zeta$-zeta potential, positive or negative, will prevent particle-particle aggregation and keep the dispersion uniform and free flowing. Additionally, viscosity as a rheological parameter is crucial in ceramic processing, since the suspension is required to have a viscosity low enough to be able to cast accurately into the desired shape. Figure 8 shows the effect of $\mathrm{pH}$ on the relative density of the HP and TM300 sintered bodies (sintering temperature $1250^{\circ} \mathrm{C}$ ) produced by slip casting. The respective green bodies from $25 \mathrm{wt} \%$ of HP and TM300 suspensions were prepared by varying the $\mathrm{pH}$. After heattreatment at $1250^{\circ} \mathrm{C}$ for $60 \mathrm{~min}$, density was measured. The relative density of the HP sintered bodies always remains lower than that obtained from the TM300 and gradually decreases with increasing $\mathrm{pH}$. These results are consistent with the observed effect of $\mathrm{pH}$ on the viscosity, $\zeta$-potential and therefore, agglomeration of the powders in the aqueous suspensions.

The effect of heating temperature on the relative density was also studied. The green bodies were prepared from a Newtonian suspension with $35 \mathrm{wt} \%$ of solid content. The bodies were heattreated at $400,600,900$ and $1250^{\circ} \mathrm{C}$. Figure 9 shows the relative density of the bodies as a function of heating temperature. Since the degree of shrinkage of the dry green body prepared with $\mathrm{HP}$ is minor ( $7.5 \%$ vs $50 \%$ of volume for TM300), its density is smaller as a result of the higher porosity generated by the interstitial spaces created by the stacking of more anisotropic particles. In both cases, the relative density seems to remain more or less constant from 400 to $900^{\circ} \mathrm{C}$ and then drastically increases with higher temperatures. This variation can be attributed to the change of phase experienced for $\gamma$-alumina which transforms to theta alumina at around $900^{\circ} \mathrm{C}$ and finally to alpha alumina at around $1200^{\circ} \mathrm{C}$. The real density (calculated by pycnometry) used for alpha alumina was $3.98 \mathrm{~g} \mathrm{~cm}^{-3}$ and for theta and gamma alumina 3.37 and $3.1 \mathrm{~g} \mathrm{~cm}^{-3}$ respectively. The relative density of HP bodies was significantly lower in all cases than that obtained for TM300, which seems to result from the difference of the 

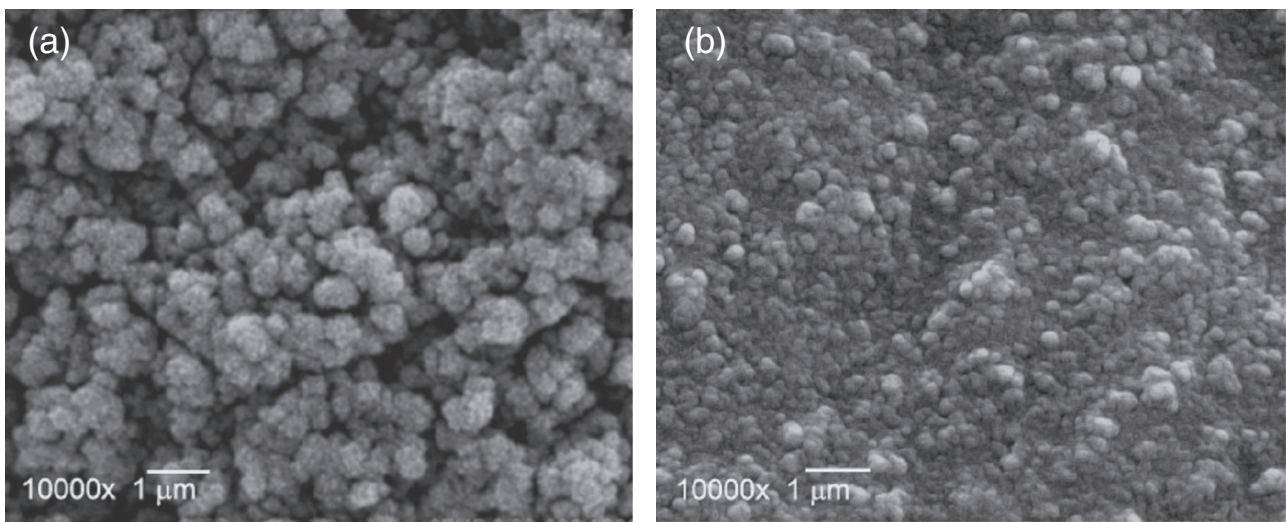

Fig. 10. SEM micrographs of (a) HP and (b) TM300 bodies prepared by slip cast with $25 \mathrm{wt} \%$ of solid loading, pH 4 and heated at $900^{\circ} \mathrm{C}$

viscosities of the original suspensions (Fig. 6). This result is in agreement with $\zeta$-potential data.

Figure 10 shows the morphology observed by SEM of the heat-treated bodies at $900^{\circ} \mathrm{C}$ where bigger spheroidal agglomerates and higher porosity can be observed for the HP body [Fig. 10(a)] in comparison with the smaller and more spherical agglomerates conforming a more compact structure for TM300 [Fig. 10(b)]. Such differences are derived from the distinct rheological characteristics of the dispersions, which are in turn a consequence of the powder morphology. Therefore, fibrillar nanoparticles with high surface area generate more porous compact ceramics.

\section{Conclusions}

The final densities and porosities of green and heat-treated bodies consisting of nanosized $\gamma$-alumina were affected by the rheology of the original suspensions. The castability of a $\gamma$ alumina suspension depends on $\mathrm{pH}$, solid loading, and powder morphology. The $\gamma$-alumina derived from homogeneous precipitation has a fibrous morphology with a high specific surface area, which makes necessary to shift to a lower $\mathrm{pH}$ in order to obtain Newtonian flow. Furthermore, the limit of solid content ( $35 \mathrm{wt} \%$ ) for castable HP suspension was lower than (45 wt \%) commercial $\gamma$-alumina TM300. In all cases, heat-treated bodies of HP $\gamma$-alumina achieve a lower density. This result is related to the spatial interstices generated between the spheroidal agglomerates conformed by nanofibers of about 25 of aspect ratio in comparison with the aspect ratio of about 1 for the TM300 nanopowder.

Acknowledgments We would like to express our gratitude to Nagaoka University of Technology 1603-1 Kamitomioka, Nagaoka, Japan 940-2188, for the assistance in the use of the Physica MCR Rheometer.

\section{References}

1) S. A. Simakov and Y. Tsur, J. Nanopart. Res., 9, 403-417 (2007).

2) M. Menon, S. Decourcelle, S. Ramousse and P. H. Larsen, J. Am. Ceram. Soc., 89, 457-464 (2006).

3) M. Hashiba, A. Harada, N. Adachi, S. Obata, O. Sakurada and K. Hiramatsu, Mater. Trans., 46, 2647-2650 (2005).

4) L. C. Guo, Y. Zhang, N. Uchida and K. Uematsu, J. Am. Ceram. Soc., 81, 549-556 (1998).

5) J. Moon, J. E. Grau, M. J. Cima and E. M. Sachs, J. Am. Ceram. Soc., 83, 2401-2408 (2000).
6) N. Omura, Y. Hotta, K. Sato, Y. Kinemuchi, S. Kume and K. Watari, J. Am. Ceram. Soc., 89, 2738-2743 (2006).

7) J. A. Lewis, J. Am. Ceram. Soc., 83, 2341-2359 (2000).

8) T. A. Ring, "Fundamentals of Ceramic Powder Processing and Synthesis", Academic Press, Inc., San Diego, California (1996), pp. 550-585.

9) O. Burgos-Montes and R. Moreno, J. Eur. Ceram. Soc., 29, 603-610 (2009).

10) K. Lu, C. S. Kessler and R. M. Davis, J. Am. Ceram. Soc., 89, 2459-2465 (2006).

11) C. Li and M. Akinc, J. Am. Ceram. Soc., 88, 1448-1454 (2005).

12) G. V. Franks and Y. Gan, J. Am. Ceram. Soc., 90, 3373-3388 (2007).

13) P. Bowen, C. Carry, D. Luxembourg and H. Hofmann, Powder Technol., 157, 100-107 (2005).

14) S. Manjula, S. Mahesh Kumar, G. M. Madhu, R. Suresh and M. A. Lourdu Anthony Raj, Ceramica, 51, 121-127 (2005).

15) S. Sugita, C. Contreras, H. Juárez, A. Aguilera and J. Serrato, Int. J. Inorg. Mater., 3, 625-632 (2001).

16) R. E. Simpson, II, C. Habeger, A. Rabinovich and J. H. Adair, J. Am. Ceram. Soc., 81, 1377-1379 (1998).

17) R. Román, T. Hernández and M. González, Bol. Soc. Esp. Ceram. V., 47, 311-315 (2008).

18) B. K. Park and J. M. Jin, J. Ceram. Process. Rese., 9, 204-208 (2008).

19) G. Paglia, C. E. Buckley, A. L. Rohl, R. D. Hart, K. Winter, A. J. Studer, B. A. Hunter and J. V. Hanna, Chem. Mater., 16, 220-236 (2004).

20) F. Tang, T. Uchikoshi, K. Ozawa and Y. Sakka, Mater. Res. Bull., 37, 653-660 (2002).

21) X. Carrier, E. Marceau, J. F. Lambert and M. Che, J. Colloid Interface Sci., 308, 429-437 (2007).

22) J. K. Beattie and A. Djerdjev, J. Am. Ceram. Soc., 83, 23602364 (2000).

23) C. Perego and P. Villa, Catal. Today, 34, 281-305 (1997).

24) D. J. Kim, H. Kim and J. K. Lee, J. Mater. Sci., 33, 2931-2935 (1998).

25) C. Gutiérrez, J. Sánchez-Herencia and R. Moreno, Bol. Soc. Esp. Ceram. V., 39, 105-117 (2000).

26) E. Behzadfar, M. H. Abdolrasouli, F. Sharif and H. Nazockdast, Braz. J. Chem. Eng., 26, 713-721 (2009).

27) Y. Hotta, N. Omura, K. Sato and K. Watari, J. Eur. Ceram. Soc., 27, 753-757 (2007).

28) A. C. Vieira Coelho, G. A. Rocha, P. Souza Santos, H. Souza Santos and P. K. Kiyohara, Rev. Matér., 13, 329-341 (2008).

29) J. R. Viguié, B. Sukmanowski, F. Nölting and X. Royer, Eng Aspects., 302, 269-275 (2007).

30) S. Kato, H. Unuma, T. Ota and M. Takahashi, J. Am. Ceram. Soc., 83, 986-988 (2000). 